Article

\title{
General Intermediates for the Synthesis of 6-C-Alkylated DMDP-Related Natural Products
}

\author{
Mu-Hua Huang ${ }^{1,2}$, Yi-Xian Li ${ }^{1}$, Yue-Mei Jia ${ }^{1}$ and Chu-Yi Yu ${ }^{1, *}$ \\ 1 Beijing National Laboratory for Molecular Science (BNLMS), \\ CAS Key Laboratory of Molecular Recognition and Function, \\ Institute of Chemistry, Chinese Academy of Sciences, Beijing 100191, China \\ 2 School of Materials Science and Engineering, Beijing Institute of Technology, \\ Beijing 100081, China \\ * Author to whom correspondence should be addressed; E-Mail: yucy@iccas.ac.cn.
}

Received: 8 May 2013; in revised form: 24 May 2013 / Accepted: 27 May 2013 /

Published: 7 June 2013

\begin{abstract}
Protected L-homoDMDP en-8 and its C-6 epimer en-7 were prepared through two different pathways starting from the vinylpyrrolidine en-9. Based on the NMR and X-ray analysis, the stereochemistry of homoDMDP at C-6 was confirmed to be consistent with reported data. Compounds $e n-\mathbf{7}$ and $e n-\mathbf{8}$ are general intermediates for the synthesis of a series of 6-C-alkylated DMDP-related natural products, such as broussonetine $\mathrm{G}$, homoDMDP-7- $O$-apioside, homoDMDP-7- $O$ - $\beta$-D-xyloside and so on.
\end{abstract}

Keywords: homo-DMDP; broussonetine G; homoDMDP-7-O-apioside; glycosidase inhibitors; cyclic nitrones

\section{Introduction}

The naturally occurring polyhydroxylated alkaloid $(2 R, 3 R, 4 R, 5 R)$-2,5-dihydroxymethyl-3,4dihydroxypyrrolidine (DMDP, 1, Figure 1) [1] has become a key iminosugar in the field of glycosidase inhibitors [2-4]. 6-C-Butyl-DMDP (2, Figure 1) [5] and broussonetine G (3, Figure 1) [6-8] represent a class of 6- $C$-alkyl-DMDP natural products with high $\beta$-glycosidase inhibitory properties. Another 6- $C$ alkyl-DMDP example is 2,5-dideoxy-2,5-imino-glycero-D,L-manno-heptitol (homo-DMDP, 4, Figure 1), which was synthesized by the Wong group [9] in 1995 before it was isolated in 1997 [10] from Hyacinthaceae plants. In addition, 7-O-glycosylated homoDMDP natural products such as 
homoDMDP-7-O-apioside (5, Figure 1) and homoDMDP-7- $O-\beta-D-x y l o s i d e ~(6$, Figure 1), isolated from bluebell, also showed very highly selective glycosidase inhibition properties [11]. Interestingly, the stereochemistry at C-6 of the above mentioned 6- $C$-alkyl-DMDP natural products was not reported upon their isolation owing to limitations on NMR analysis due to the scarce amounts of substance available from natural sources. An unambiguous stereochemistry elucidation of the homoDMDP-related natural products is needed for establishing the structure-activity relationships of these compounds in medicinal chemistry, and a collective synthesis of these natural products based on a common intermediate would be of great significance [12] for speeding up the chemical biology study of these fascinating molecules.

Figure 1. DMDP, homoDMDP and 6- $C$-alkyl-DMDP natural products.
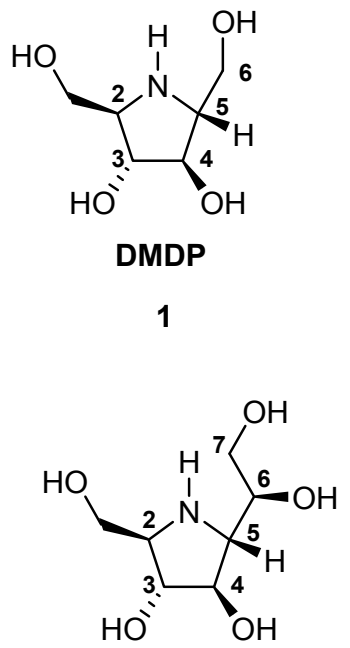

homoDMDP

4

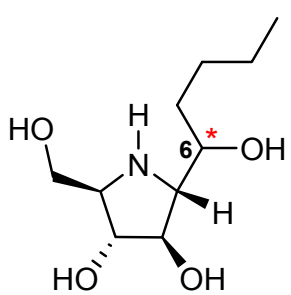

6-C-Butyl-DMDP

2

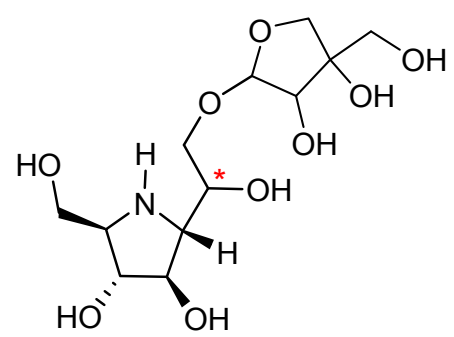

HomoDMDP-7-O-apioside

5

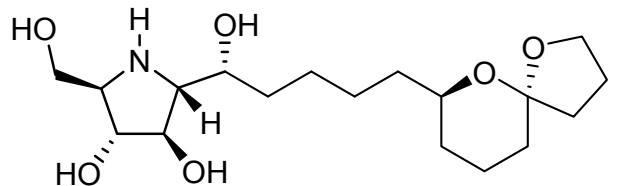

Broussonetine G

3

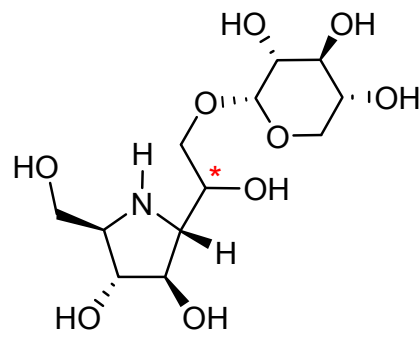

homoDMDP-7-O- $\beta-$
D-xylopyranoside

6

In recent years, some of the synthetic L-enantiomers of iminosugars, were found to be even more powerful and specific glycosidase inhibitors than the natural products, e.g., L-DMDP vs. DMDP [13], (+)-steviamine $v s$. natural (-)-steviamine [14]. These experimental results provided a promising new direction for pharmaceutical chemistry. However, a substantive explanation for this fact requires more information about the stereochemistry of the relevant compounds. In order to promote research on iminosugars, our group has developed a powerful strategy for the synthesis of DMDP-related natural products or analogues via cyclic nitrone intermediates [15], which has led to easy access to a series of DMDP-related iminosugars [13,14,16-21], as well as glycosidase inhibitors.

Although Wong et al. had indicated the absolute configuration of homoDMDP to be $(2 R, 3 R, 4 R, 5 R, 6 S)$ based on their enantiospecific synthesis of a series of five-membered iminosugars [22], no direct experimental proof was available until our group reported the synthesis of L-homoDMDP [19]. There, we disclosed the stereochemistry of L-homoDMDP determined by analyzing the 2D-NMR of an oxazinone intermediate, a conformation-locked L-homoDMDP. In this article, we report a further confirmation of L-homoDMDP's stereochemistry based on X-ray and 2D-NMR analysis of its oxazolidinone derivatives. In addition, both epimers of protected L-homoDMDP at C-6 
were obtained readily, which are common intermediates for enantiomers of 6- $C$-alkyl-DMDP natural products such as homoDMDP-7- $O$-apioside and homoDMDP-7-O- $\beta$-D-xyloside.

\section{Results and Discussion}

6-C-Alkyl-DMDP iminosugars have attracted lots of attention, and several syntheses are available in the literature [7,22]. However, these syntheses are either tedious or the method was only suitable for a specific compound. In order to solve the material supply problem and speed up the study of glycosidase inhibition, a practical synthesis of this family of natural products is in great demand. In this regard, the collective synthesis strategy [12] relying on an advanced common intermediate provides a good opportunity. In addition, a full assignment of the stereochemistry of 6-C-alkyl-DMDP iminosugars requires both epimers.

Taking homo-DMDP-7-O-apioside and homo-DMDP-7- $O$ - $\beta$-D-xylopyranoside as examples, we envisioned that it is necessary to obtain both C-6 epimers $\mathbf{7}$ and $\mathbf{8}$, which could be reached from the same intermediate $\mathbf{9}$ (Scheme 1). Furthermore, conformation-locked molecules $\mathbf{7}$ and $\mathbf{8}$ are very good intermediates for stereochemistry assignment based on 2D-NMR analysis, and all the isomers or intermediates represent interesting medicinal chemistry targets. From a retrosynthesis point of view, homoDMDP-related natural products 5 and $\mathbf{6}$ could be synthesized via glycosylation of alcohol $\mathbf{7}$ or $\mathbf{8}$, which could be accessed from all-trans substituted pyrrolidine 9 by alkene oxidation. Based on the well-developed chemistry of highly stereoselective addition of organometallic reagents to cyclic nitrones [23-25], pyrrolidine 9 could be prepared on a large scale with extreme purity.

Scheme 1. Synthesis of en-7.
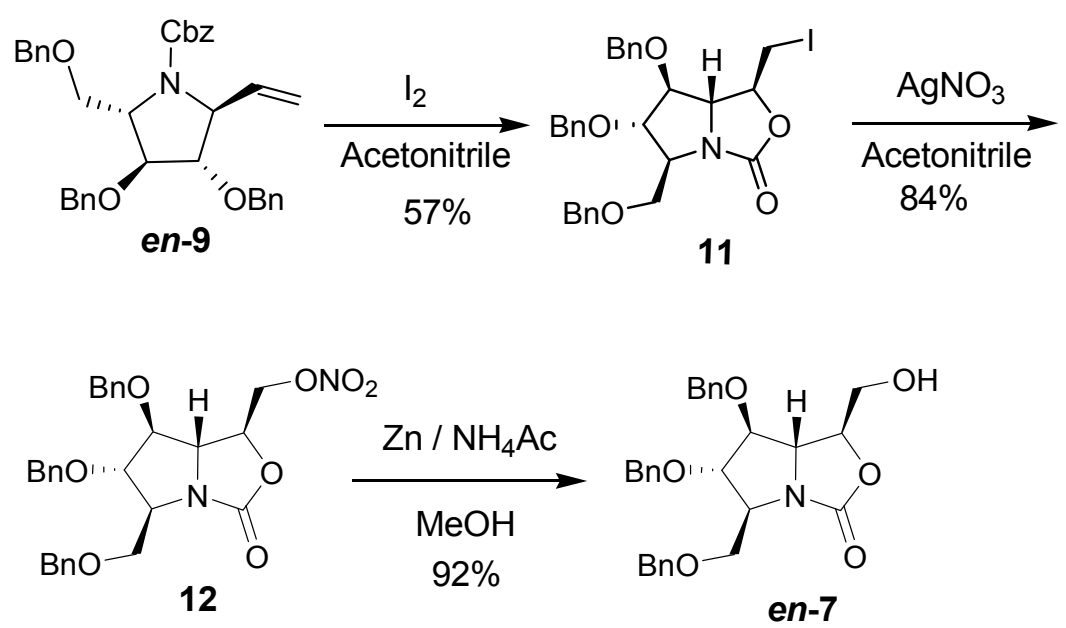

With grams of vinyl-containing pyrrolidine en-9 [19] in hand, the synthesis of en-7 and en-8 was attempted (Scheme 1). The terminal alkene en-9 was treated with iodine in acetonitrile, and the oxazolidinone 11 was obtained in $57 \%$ yield, with structure supported by its IR data $\left(v_{\max } 1,762 \mathrm{~cm}^{-1}\right)$ and ${ }^{13} \mathrm{C}$-NMR spectrum ( $\delta 159.98 \mathrm{ppm}$ ). Its relative configuration was studied by its NOESY spectrum based on the full assignment of all protons through ${ }^{1} \mathrm{H}-\mathrm{NMR}$ and 2D-NMR (COSY, HMBC). The strong correlations observed between $\mathrm{H}-3 / \mathrm{H}-1$ as well as $\mathrm{H}-5 / \mathrm{H}-1$ revealed that $\mathrm{H}-1, \mathrm{H}-3$ and $\mathrm{H}-5$ were on the underside of the pyrrolidine ring (Figure 2), while the strong correlations between $\mathrm{H}-2 / \mathrm{H}-4$ 
showed they were on the same side. i.e., the pyrrolidine was all-trans substituted, which was consistent with the previous results reported by our group. The correlations between $\mathrm{H}-5 / \mathrm{H}-1$ as well as $\mathrm{H}-5 / \mathrm{H}-7$ showed the $\mathrm{C}(7) \mathrm{H}_{2} \mathrm{I}$ was on the upper side of the oxazolidinone ring. Furthermore, the above determination of relative as well as absolute configuration of the oxazolidinone 11 was unambiguously confirmed to be $(2 S, 3 S, 4 S, 5 R, 6 S)$ by X-ray diffraction [26]. The treatment of iodide $\mathbf{1 1}$ by silver nitrate followed by reductive hydrolysis [27] furnished the alcohol en-7 in a total yield of 77\% over two steps. Since during these two steps the stereocenters have not been touched, the streochemistry of en-7 was determined to be $(2 S, 3 S, 4 S, 5 S, 6 S)$.

Figure 2. Stereochemistry elucidation of $\mathbf{1 1}$ by NOESY and X-ray analysis.

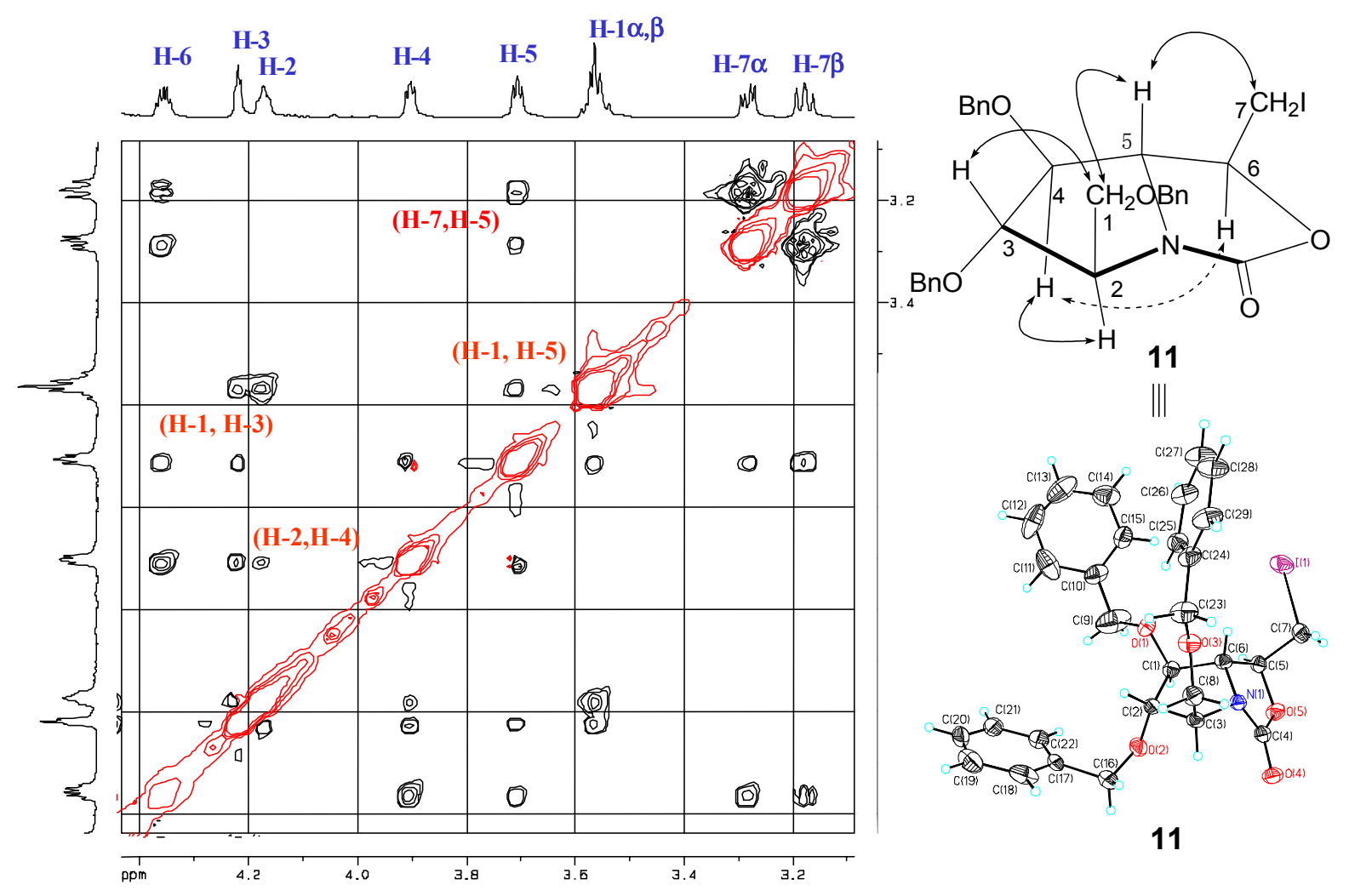

In the course of the synthesis of L-homoDMDP, we were delighted to find that the major product $\mathbf{1 3}$ (Scheme 2) obtained from dihydroxylation on terminal alkene en-9 was the right diastereomer for L-homoDMDP, which was prepared by the hydrogenation on diol $\mathbf{1 3}$ to remove the protecting groups. The stereochemistry of L-homoDMDP was confirmed to be $(2 S, 3 S, 4 S, 5 S, 6 R)$ based on a conformationlocked oxazinone intermediate [19]. In order to provide more evidence for the stereochemistry confirmation of homoDMDP, as well as common intermediates in the collective synthesis of homoDMDP-related pyrrolidine natural products, we decided to make the correseponding oxazolidinone derivatives. The diol 13 was selectively protected as trityl ether 14, the secondary alcohol 14 was then treated with alkaline solution, and the oxazolidinone 15 was obtained in $69 \%$ yield over two steps. After treatment of trityl ether $\mathbf{1 5}$ with mineral acid, the alcohol en-8 was obtained in $85 \%$ yield (Scheme 2). Conformation of the oxazolidinone structure was supported by its IR data $\left(v_{\max } 1,758 \mathrm{~cm}^{-1}\right)$ and ${ }^{13} \mathrm{C}-\mathrm{NMR}$ spectrum $(\delta 160.03 \mathrm{ppm})$. 
Scheme 2. Synthesis of en-8.<smiles>C=C[C@H]1[C@@H](Br)[C@@H](OCc2ccccc2)[C@H](COc2ccccc2)N1C(=O)OCc1ccccc1</smiles>

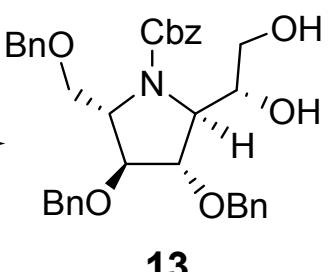

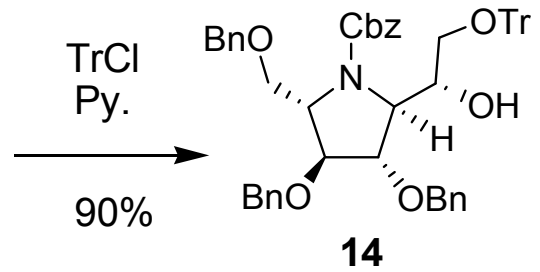

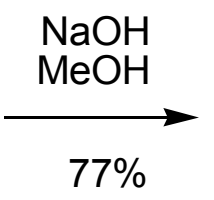

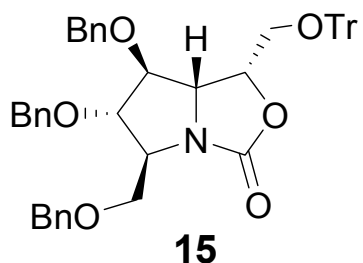

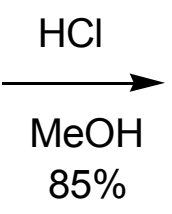

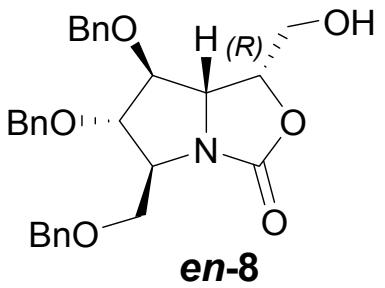

Similarly, the relative configuration of alcohol en-8 was assigned unambiguously through NOESY spectrum (Figure 3). The strong correlations observed between $\mathrm{H}-3 / \mathrm{H}-1, \mathrm{H}-5 / \mathrm{H}-1$, as well as $\mathrm{H}-5 / \mathrm{H}-3$ revealed $\mathrm{H}-1, \mathrm{H}-3$ and $\mathrm{H}-5$ were on the upper side of the pyrrolidine ring, i.e., the pyrrolidine was all-trans-substituted. The correlations between $\mathrm{H}-7 / \mathrm{H}-4$ showed the $\mathrm{C}(7) \mathrm{H}_{2} \mathrm{OH}$ was on the underside of the oxazolidinone ring. Based on the above analysis as well as comparison with en-7, the stereochemistry of en-8 was deduced to be $(2 S, 3 S, 4 S, 5 S, 6 R)$, and the configuration of homoDMDP was determined as $(2 R, 3 R, 4 R, 5 R, 6 S)$, which was consistent with reported data [19].

Figure 3. Stereochemistry elucidation of en-8 by NOESY.
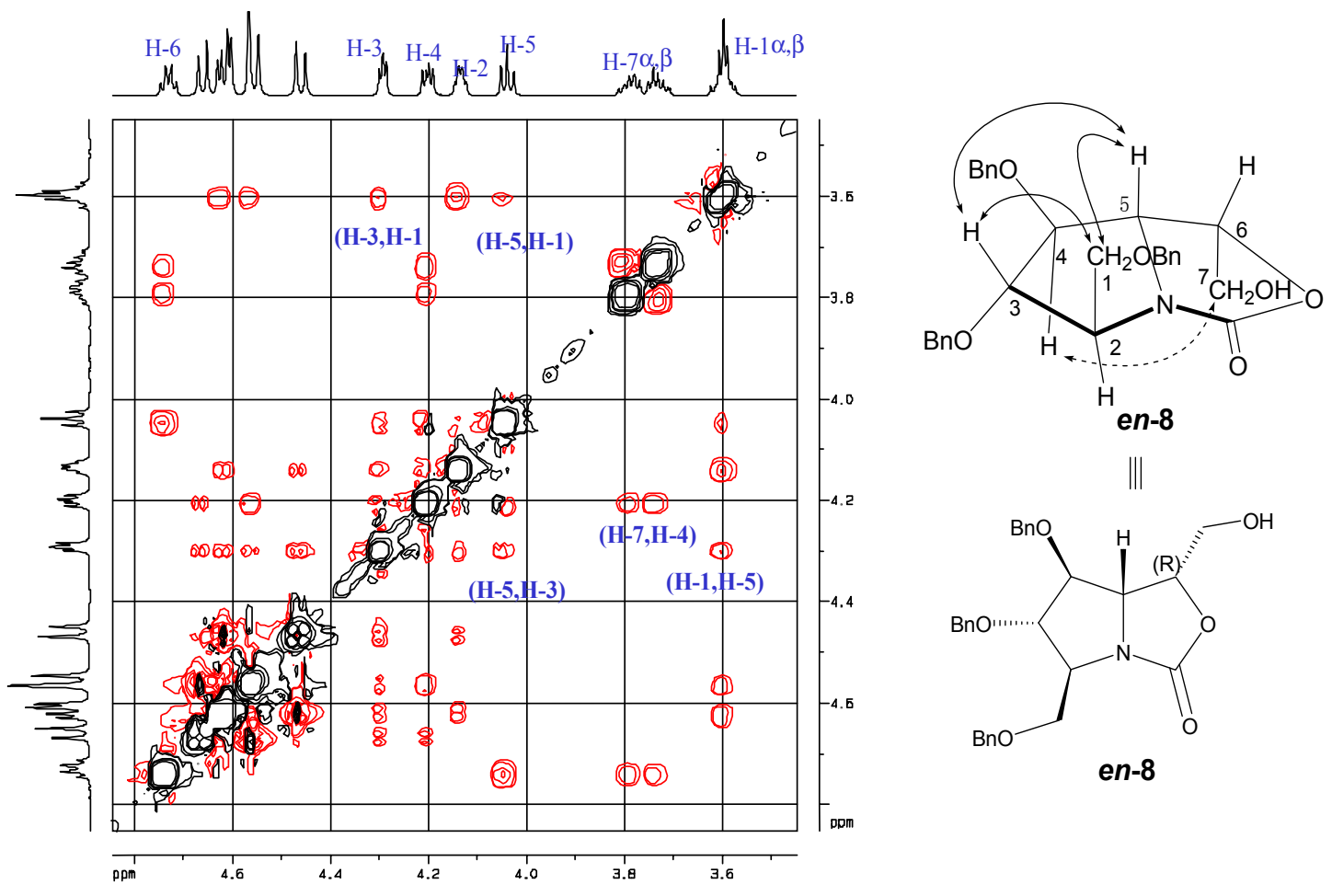
With both C-6 epimers en-7 and en-8 in hand, the syntheses of the enantiomers of homo-DMDP-7O-apioside and homo-DMDP-7-O- $\beta$-D-xylopyranoside by glycosylation of en-7 and en-8 were on the right course. In addition, iodide 11 represents an ideal intermediate for the total synthesis of enantiomers of 6-C-alkyl-DMDP natural products such as L-6- $C$-butyl-DMDP and (+)-broussonetine G. For the total synthesis of the natural 6-C-alkyl-DMDP pyrrolidines, we are currently working on the synthesis of cyclic nitrone 10. The relevant results will be reported in due course.

\section{Experimental}

\subsection{General}

All reagents were used as received from commercial sources without further purification or prepared as described in the literature. Tetrahydrofuran was distilled from sodium and benzophenone immediately before use. Reaction mixtures were stirred using Teflon-coated magnetic stir bars. Analytical TLC was performed with $0.20 \mathrm{~mm}$ silica gel 60F plates with $254 \mathrm{~nm}$ fluorescent indicator. Plates were visualized by ultraviolet light and treatment with Pancaldi reagent $\left[\left(\mathrm{NH}_{4}\right)_{6} \mathrm{MoO}_{4}\right.$, $\mathrm{Ce}\left(\mathrm{SO}_{4}\right)_{2}, \mathrm{H}_{2} \mathrm{SO}_{4}, \mathrm{H}_{2} \mathrm{O}$ ] or $0.5 \%$ ninhydrin in acetone stain, followed by gentle heating. Chromatographic purification of products was carried out by flash chromatography on silica gel (230-400 mesh) as well as on the $001 \times 7\left(732^{\#}\right)$ strong acid styrene cation exchange resin (Tianjin Kermel Chemical Reagent Development Center, Tianjin, China). Melting points were determined using an Electrothermal melting point apparatus. Both melting points and boiling points are uncorrected. Infrared spectra were recorded on a JASCO FT/IR-480 plus Fourier transform spectrometer. NMR spectra were measured in $\mathrm{CDCl}_{3}$ (with TMS as internal standard) or $\mathrm{D}_{2} \mathrm{O}$ on a Bruker AV300 and AV600 magnetic resonance spectrometers. Chemical shifts $(\delta)$ are reported in ppm, and coupling constants $(J)$ are in Hz. The following abbreviations were used to explain the multiplicities: $\mathrm{s}=$ singlet, $\mathrm{d}=$ doublet, $\mathrm{t}=$ triplet, $\mathrm{q}=$ quartet, $\mathrm{m}=$ multiplet. High-resolution mass spectra (HRMS) were recorded on an APEXII FT-ICR (SIMS) mass spectrometer. Polarimetry was carried out using an Optical Activity AA-10R polarimeter and the measurements were made at the sodium D-line with a $0.5 \mathrm{dm}$ pathlength cell. Concentrations (c) are given in gram per $100 \mathrm{~mL}$. Single-crystal X-ray diffraction was collected on a Rigaku RAPID-AUTO diffractometer.

(1S,5S,6S,7S,7aR)-6,7-bis(Benzyloxy)-5-((benzyloxy)methyl)-tetrahydro-1-(iodomethyl)pyrrolo[1,2-c] oxazol-3(1H)-one (11). To a solution of alkene en-9 $(0.22 \mathrm{~g}, 0.39 \mathrm{mmol})$ in acetonitrile $(3 \mathrm{~mL})$, iodine $(0.36 \mathrm{~g}, 1.4 \mathrm{mmol})$ was slowly added, and the resulting purple mixture was stirred at r.t. for $3.5 \mathrm{~h}$. The reaction was then quenched by adding sat. aqueous $\mathrm{Na}_{2} \mathrm{~S}_{2} \mathrm{O}_{3}$, and extracted with EtOAc. The combined organic extracts were dried over anhydrous $\mathrm{Na}_{2} \mathrm{SO}_{4}$, concentrated, the residue was purified by FCC (silica gel, eluted with $10 \%-20 \%$ EtOAc in petroleum ether) to give the title oxazolidinone $\mathbf{1 1}$ as a colorless crystalline product $(0.13 \mathrm{~g}$, yield $57 \%)$. IR $\left(\mathrm{KBr}, \mathrm{cm}^{-1}\right) 1,767(\mathrm{vs}), 1,455(\mathrm{w}), 1,362(\mathrm{w})$, $1,213(\mathrm{w}), 1,100(\mathrm{w}) .[\alpha]_{D}^{25}=+55.8^{\circ}\left(\mathrm{c} 0.86, \mathrm{CHCl}_{3}\right) .{ }^{1} \mathrm{H}-\mathrm{NMR}\left(\mathrm{CDCl}_{3}, 600 \mathrm{MHz}\right): \delta(\mathrm{ppm})$ 7.35-7.25 (m, 15H), 4.64-4.44 (m, 6H), 4.37-4.34 (m, 1H), $4.22(\mathrm{t}, 1 \mathrm{H}, J=2.7 \mathrm{~Hz}), 4.17(\mathrm{t}, 1 \mathrm{H}$, $J=6.6 \mathrm{~Hz}), 3.90(\mathrm{dd}, 1 \mathrm{H}, J=3.8$ and $5.5 \mathrm{~Hz}), 3.71(\mathrm{t}, 1 \mathrm{H}, J=4.3 \mathrm{~Hz}), 3.59-3.53(\mathrm{~m}, 2 \mathrm{H}), 3.28(\mathrm{dd}$, $1 \mathrm{H}, J=4.3$ and $10.4 \mathrm{~Hz}), 3.18(\mathrm{dd}, 1 \mathrm{H}, J=8.3$ and $10.1 \mathrm{~Hz}) \cdot{ }^{13} \mathrm{C}-\mathrm{NMR}\left(\mathrm{CDCl}_{3}, 75 \mathrm{MHz}\right): \delta(\mathrm{ppm})$ $160.00,137.84,137.36,137.30,128.64,128.51,128.45,128.21,127.96,127.91,127.78,127.70$, 
87.55, 84.99, 78.26, 73.30, 72.74, 71.94, 69.32, 68.12, 62.76, 5.90. DEPT-135 $\left(\mathrm{CDCl}_{3}, 75 \mathrm{MHz}\right) \delta$ (ppm): Positive: 128.64, 128.51, 128.45, 128.22, 127.96, 127.91, 127.78, 127.70, 87.55, 84.98, 78.26, 68.11, 62.75; Negative: 73.30, 72.74, 71.94, 69.32, 5.91. FTICR-MS $m / z: 600.1243[\mathrm{M}+\mathrm{H}]^{+}$ $\left(\mathrm{C}_{29} \mathrm{H}_{31} \mathrm{NO}_{5} \mathrm{I}^{+}\right.$requires 600.1241).

(1S,5S,6S,7S,7aR)-6,7-bis(Benzyloxy)-5-((benzyloxy)methyl)-tetrahydro-1-(O-nitroate-methyl)pyrrolo[1,2-c] oxazol-3(1H)-one (12). To a solution of iodide $11(0.21 \mathrm{~g}, 0.35 \mathrm{mmol})$ in acetonitrile $(6 \mathrm{~mL})$ silver nitrate $(0.18 \mathrm{~g}, 1.0 \mathrm{mmol})$ was added, the resulting reaction mixture was heated to reflux for $40 \mathrm{~h}$. The resulting solid was filtered off, the filtrates was concentrated, the residue was purified by FCC (silica gel, eluted with $10-30 \%$ EtOAc in petroleum ether) to give the nitrate $12(0.16 \mathrm{~g}, 84 \%$ yield $)$ as colorless syrup. IR (KBr, cm $\left.{ }^{-1}\right)$ : 2,864 (w), 1,765 (vs), 1,638 (s), 1,279 (s), 1,096 (m), 739 (m), 698 (m). $[\alpha]_{D}^{25}=+22.1^{\circ}\left(c\right.$ 1.0, $\left.\mathrm{CHCl}_{3}\right) .{ }^{1} \mathrm{H}-\mathrm{NMR}\left(\mathrm{CDCl}_{3}, 300 \mathrm{MHz}\right): \delta(\mathrm{ppm}) 7.36-7.19(\mathrm{~m}, 15 \mathrm{H}), 4.69-4.36$ $(\mathrm{m}, 9 \mathrm{H}), 4.28(\mathrm{t}, 1 \mathrm{H}, J=3.3 \mathrm{~Hz}), 4.15(\mathrm{~d}, 1 \mathrm{H}, J=2.9 \mathrm{~Hz}), 3.90(\mathrm{dd}, 1 \mathrm{H}, J=4.0$ and $6.0 \mathrm{~Hz}), 3.68(\mathrm{~d}$, $1 \mathrm{H}, J=6.1 \mathrm{~Hz}), 3.58(\mathrm{~d}, 2 \mathrm{H}, J=5.4 \mathrm{~Hz}) .{ }^{13} \mathrm{C}-\mathrm{NMR}\left(\mathrm{CDCl}_{3}, 75 \mathrm{MHz}\right): \delta(\mathrm{ppm}) 159.30,137.75$, $137.24,128.78,128.55,128.48,128.43,128.07,127.98,127.93,127.85,127.71,87.66,85.30,74.76$, 73.35, 72.80, 72.18, 71.88, 69.43, 64.31, 62.69. DEPT-135 $\left(\mathrm{CDCl}_{3}, 75 \mathrm{MHz}\right) \delta(\mathrm{ppm})$ : Positive: $128.78,128.55,128.48,128.06,127.99,127.93,127.85,127.71,87.65,85.30,74.76,64.30,62.69$; Negative: 73.35, 72.80, 72.18, 71.88, 69.42. FTICR-MS $m / z: 535.2079[\mathrm{M}+\mathrm{H}]^{+}\left(\mathrm{C}_{29} \mathrm{H}_{31} \mathrm{~N}_{2} \mathrm{O}_{8}{ }^{+}\right.$requires 535.2075).

(1S,5S,6S,7S,7aS)-6,7-bis(Benzyloxy)-5-((benzyloxy)methyl)-tetrahydro-1-(hydroxymethyl)pyrrolo[1,2-c] oxazol-3(1H)-one (en-7). To a suspension of nitrate $12(0.10 \mathrm{~g}, 0.19 \mathrm{mmol})$ and ammonium acetate $(0.08 \mathrm{~g}, 1 \mathrm{mmol})$ in $\mathrm{MeOH}(5 \mathrm{~mL})$ was added zinc powder $(0.11 \mathrm{~g}, 1 \mathrm{mmol})$. The resulting mixture was stirred at $\mathrm{r}$. $\mathrm{t}$. The solvents were removed in vacuo, the residue was purified via FCC (silica gel, eluted with 10\%-40\% EtOAc in petroleum ether) to give the alcohol en-7 (87 mg, yield 92\%) as a colorless syrup. IR (KBr, $\left.\mathrm{cm}^{-1}\right)$ : 3,443 (w), 3,062 (vw), 3,031 (w), 2,928 (w), 2,867 (w), 1,758 (vs), $1,101(\mathrm{~m}), 1,070(\mathrm{~m}) .[\alpha]_{D}^{25}=+14.2^{\circ}\left(c 1.1, \mathrm{CHCl}_{3}\right) .{ }^{1} \mathrm{H}-\mathrm{NMR}\left(\mathrm{CDCl}_{3}, 300 \mathrm{MHz}\right): \delta(\mathrm{ppm}) 7.31-7.14$ $(\mathrm{m}, 15 \mathrm{H}), 4.31(\mathrm{dd}, 1 \mathrm{H}, J=4.0$ and $4.5 \mathrm{~Hz}), 4.22(\mathrm{t}, 1 \mathrm{H}, J=3.0 \mathrm{~Hz}), 4.18-4.09(\mathrm{~m}, 1 \mathrm{H}), 3.88(\mathrm{dd}, 1 \mathrm{H}$, $J=3.9$ and $5.9 \mathrm{~Hz}), 3.76-3.66(\mathrm{~m}, 2 \mathrm{H}), 3.63-3.49(\mathrm{~m}, 3 \mathrm{H}), 1.96(\mathrm{t}, 1 \mathrm{H}, J=6.5 \mathrm{~Hz}, \mathrm{OH}) .{ }^{13} \mathrm{C}-\mathrm{NMR}$ $\left(\mathrm{CDCl}_{3}, 75 \mathrm{MHz}\right): \delta$ (ppm) 160.24, 137.85, 137.43, 137.32, 128.65, 128.49, 128.44, 128.20, 127.94, 127.80, 127.77, 127.70, 87.89, 85.51, 80.05, 73.28, 72.50, 72.01, 69.40, 63.96, 63.55, 62.46. DEPT-135 $\left(\mathrm{CDCl}_{3}, 75 \mathrm{MHz}\right) \delta(\mathrm{ppm})$ Positive: 128.65, 128.49, 128.44, 128.21, 127.95, 127.80, 127.77, 127.70, 87.88, 85.50, 80.06, 63.95, 62.46; Negative: 73.27, 72.50, 72.01, 69.39, 63.54 . FTICR-MS $m / z$ : $490.2228[\mathrm{M}+\mathrm{H}]^{+}\left(\mathrm{C}_{29} \mathrm{H}_{32} \mathrm{NO}_{6}+\right.$ requires 490.2224).

(2S,3S,4S,5S)-Benzyl 3,4-bis(benzyloxy)-2-((benzyloxy) methyl)-5-((R)-1,2-dihydroxyethyl)pyrrolidine1-carboxylate (14). To a solution of diol $(0.22 \mathrm{~g}, 0.4 \mathrm{mmol})$ in DCM $(3 \mathrm{~mL})$ was added pyrridine $(1 \mathrm{~mL})$ and trityl chloride $(0.22 \mathrm{~g}, 0.8 \mathrm{mmol})$. The resulting reaction mixture was stirred at r.t. for $14 \mathrm{~h}$. The solvents were removed in vacuo, the residue was dissolved in EtOAc and $\mathrm{HCl}(1 \mathrm{~N})$. After extraction, the combined organics were dried over anhydrous $\mathrm{Na}_{2} \mathrm{SO}_{4}$, concentrated, the residue was purified by FCC (silica gel, elutedwith 10\%-30\% EtOAc in petroleum ether) to give the trityl ether 14

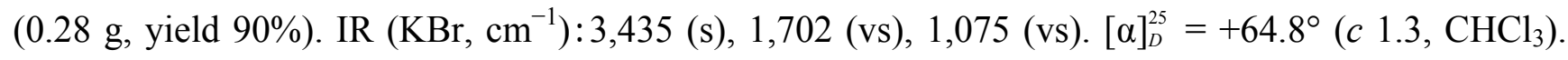


${ }^{1} \mathrm{H}-\mathrm{NMR}\left(\mathrm{CDCl}_{3}, 300 \mathrm{MHz}\right): \delta(\mathrm{ppm}) 7.56-7.03(\mathrm{~m}, 35 \mathrm{H}), 5.36-5.14(\mathrm{~m}, 2 \mathrm{H}), 4.80$ (brs, $\left.0.5 \mathrm{H}\right)$, 4.69-4.07 (m, 11H), 3.90 (brs, $0.5 \mathrm{H}), 3.85$ (dd, 1H, $J=4.1$ and $8.9 \mathrm{~Hz}), 3.63-3.54(\mathrm{~m}, 1 \mathrm{H}), 3.51-3.41$ $(\mathrm{m}, 1 \mathrm{H}), 3.06(\mathrm{t}, 0.5 \mathrm{H}, J=8.8 \mathrm{~Hz}), 2.92(\mathrm{t}, 0.5 \mathrm{H}, J=8.9 \mathrm{~Hz}) .{ }^{13} \mathrm{C}-\mathrm{NMR}\left(\mathrm{CDCl}_{3}, 75 \mathrm{MHz}\right): \delta(\mathrm{ppm})$ $154.67,154.50,143.83,143.70,138.42,138.16,137.55,137.41,136.44,136.24,128.80,128.66$, $128.61,128.39,128.23,128.00,127.89,127.68,127.62,127.57,127.35,127.26,127.08,127.05$, $86.99,86.90,82.09,81.62,81.41,80.68,73.16,73.09,71.51,71.42,68.77,68.60,67.52,67.45,67.34$, $67.17,66.70,65.97,65.74,63.35,63.06 . \mathrm{DEPT}-135\left(\mathrm{CDCl}_{3}, 300 \mathrm{MHz}\right): \delta$ (ppm) positive 128.79, $128.66,128.61,128.39,128.33,128.18,128.13,128.00,127.89,127.61,127.57,127.35,127.26$, $127.08,82.09,81.62,81.41,80.68,68.77,67.52,67.30,66.70,63.35,63.05$. negative 73.16, 73.09, $71.51,71.42,68.60,67.44,67.34,67.16,65.97,65.74$. FTICR-MS $m / z: 840.3904[\mathrm{M}+\mathrm{H}]^{+}$ $\left(\mathrm{C}_{55} \mathrm{H}_{54} \mathrm{NO}_{7}^{+}\right.$requires 862.3895); 862.3728 [M+Na] ${ }^{+}\left(\mathrm{C}_{55} \mathrm{H}_{53} \mathrm{NNaO}_{7}^{+}\right.$requires 862.3714).

(1R,5S,6S,7S,7aS)-6,7-bis(Benzyloxy)-5-((benzyloxy)methyl)-tetrahydro-1(hydroxymethyl)pyrrolo[1,2-c] -oxazol-3(1H)-one (en-8). To a solution of alcohol 14 (64 mg, $0.0076 \mathrm{mmol})$ in $\mathrm{MeOH}(3 \mathrm{~mL})$ was added $\mathrm{KOH}(80 \mathrm{mg}, 1.5 \mathrm{mmol})$. The resulting reaction mixture was stirred at r.t. for $10 \mathrm{~min}$, and then quenched by adding $\mathrm{HCl}(1 \mathrm{~N}, 5 \mathrm{~mL})$. The mixture was extracted with EtOAc, the combined organics were dried over anhydrous $\mathrm{Na}_{2} \mathrm{SO}_{4}$, concentrated, and the residue was purified by FCC (silica gel, eluted with 10\% EtOAc in petroleum ether) to give the oxazolidinone 15 (43 $\mathrm{mg}$, yield 77\%) as a colorless oil. IR (KBr, $\mathrm{cm}^{-1}$ ): 3,061 (w), 3,031 (w), 1,762 (vs), 1,494 (w), 1,450 (w), 1,364 (w), 1,211 (w), 1,093 (m). $[\alpha]_{D}^{25}=+2.9^{\circ}\left(c 0.69, \mathrm{CHCl}_{3}\right) .{ }^{1} \mathrm{H}-\mathrm{NMR}\left(\mathrm{CDCl}_{3}, 600 \mathrm{MHz}\right): \delta(\mathrm{ppm}) 7.37(\mathrm{~d}, 6 \mathrm{H}$, ArH), 7.26-7.13 (m, 20H, ArH), 7.09 (d, 2H, $J=5.2 \mathrm{~Hz}, \mathrm{ArH}), 6.91$ (d, 2H, $J=6.9 \mathrm{~Hz}, \mathrm{ArH}), 4.74$ $(\mathrm{dd}, 1 \mathrm{H}, J=6.2$ and $12.7 \mathrm{~Hz}, \mathrm{H}-1), 4.46\left(\mathrm{ABQ}, 2 \mathrm{H}, J=12.0 \mathrm{~Hz}, \mathrm{PhCH}_{2} \mathrm{O}\right), 4.37(\mathrm{~d}, 1 \mathrm{H}, J=11.8 \mathrm{~Hz}$, $\left.\mathrm{PhCH}_{2} \mathrm{O}\right), 4.23\left(\mathrm{~d}, 1 \mathrm{H}, J=11.8 \mathrm{~Hz}, \mathrm{PhCH}_{2} \mathrm{O}\right), 4.24\left(\mathrm{~d}, 1 \mathrm{H}, J=11.2 \mathrm{~Hz}, \mathrm{PhCH}_{2} \mathrm{O}\right), 4.06(\mathrm{~d}, 1 \mathrm{H}$, $J=11.1 \mathrm{~Hz}, \mathrm{PhCH}_{2} \mathrm{O}$ ), 4.08-4.05 (m, 2H, H-5 and H-6), 3.93 (t, 1H, J= 7.2 Hz, H-7a), 3.87 (dd, 1H, $J=3.6$ and $6.4 \mathrm{~Hz}, \mathrm{H}-7), 3.50(\mathrm{~d}, 2 \mathrm{H}, J=5.7 \mathrm{~Hz} \mathrm{H}-9), 3.38(\mathrm{dd}, 1 \mathrm{H}, J=6.3$ and $10.5 \mathrm{~Hz}, \mathrm{H}-8), 3.28$ (dd, $1 \mathrm{H}, J=4.4$ and $10.5 \mathrm{~Hz}, \mathrm{H}-8) .{ }^{13} \mathrm{C}-\mathrm{NMR}\left(\mathrm{CDCl}_{3}, 75 \mathrm{MHz}\right): \delta(\mathrm{ppm}) 160.07,143.27,137.81$, $137.41,137.30,137.41,137.30,128.64,128.41,128.33,127.97,127.80,127.75,127.67,127.46$, 127.24, 87.31, 85.84, 83.19, 77.44, 76.59, 75.29, 73.28, 72.24, 71.66, 69.63, 64.09, 62.67, 62.37. FTICR-MS $m / z: 732.3309[\mathrm{M}+\mathrm{H}]^{+}\left(\mathrm{C}_{48} \mathrm{H}_{46} \mathrm{NO}_{6}{ }^{+}\right.$requires 732.3319$)$.

(1R,5S,6S,7S,7aS)-6,7-bis(Benzyloxy)-5-((benzyloxy)methyl)-tetrahydro-1(hydroxymethyl)pyrrolo[1,2-c] -oxazol-3(1H)-one (en-8). To a solution of oxazolidinone 15 (102 mg, $0.014 \mathrm{mmol})$ in $\mathrm{MeOH}$ $(5 \mathrm{~mL})$ was added 5 drops of concentrated $\mathrm{HCl}$, the reaction mixture was stirred at r.t. for 10 mins. TLC revealed the complete disappearance of starting material, the reaction was quenched by adding sat. aqueous $\mathrm{NaHCO}_{3}$. The mixture was extracted with EtOAc, the combined organics were dried over anhydrous $\mathrm{Na}_{2} \mathrm{SO}_{4}$, concentrated, the residue was purified by FCC (silica gel, eluted with 10\%-50\% EtOAc in petroleum ether) to give the oxazolidinone en-8 (58 $\mathrm{mg}$, yield $85 \%)$ as a colorless syrup. IR $\left(\mathrm{KBr}, \mathrm{cm}^{-1}\right)$ 3,442 (w), 3,062 (vw), 3,031 (vw), 2,868 (w), 1,758 (vs), 1,497 (vw), 1,454 (w), 1,364 (w), 1,209 (w), 1,071 (m). $[\alpha]_{D}^{25}=-5.1^{\circ}\left(c\right.$ 1.9, $\left.\mathrm{CHCl}_{3}\right) ;{ }^{1} \mathrm{H}-\mathrm{NMR}\left(\mathrm{CDCl}_{3}, 600 \mathrm{MHz}\right): \delta(\mathrm{ppm})$ $7.35-7.24(\mathrm{~m}, 15 \mathrm{H}), 4.71(\mathrm{dd}, 1 \mathrm{H}, J=5.9$ and $13.6 \mathrm{~Hz}), 4.63(\mathrm{~d}, 1 \mathrm{H}, J=11.4 \mathrm{~Hz}), 4.59(\mathrm{~d}, 1 \mathrm{H}$, $J=12.0 \mathrm{~Hz}), 4.59(\mathrm{~d}, 1 \mathrm{H}, J=11.5 \mathrm{~Hz}), 4.53(\mathrm{~d}, 2 \mathrm{H}, J=12.4 \mathrm{~Hz}), 4.43(\mathrm{~d}, 1 \mathrm{H}, J=11.6 \mathrm{~Hz}), 4.27(\mathrm{dd}$, $1 \mathrm{H}, J=3.8$ and $4.5 \mathrm{~Hz}), 4.18(\mathrm{dd}, 1 \mathrm{H}, J=4.8$ and $8.0 \mathrm{~Hz}), 4.11(\mathrm{dd}, 1 \mathrm{H}, J=5.0$ and $8.7 \mathrm{~Hz}), 4.02$ 
(t, 1H, $J=7.9 \mathrm{~Hz}), 3.78-3.70(\mathrm{~m}, 2 \mathrm{H}), 3.60-3.55(\mathrm{~m}, 2 \mathrm{H}), 2.23(\mathrm{t}, 1 \mathrm{H}, J=6.6 \mathrm{~Hz}, \mathrm{OH}) .{ }^{13} \mathrm{C}-\mathrm{NMR}$ $\left(\mathrm{CDCl}_{3}, 75 \mathrm{MHz}\right): \delta(\mathrm{ppm}) 160.03,137.69,137.24,136.78,128.56,128.50,128.33,128.28,128.06$, $127.89,127.78,86.14,81.47,75.35,73.41,72.36,72.28,70.23,63.11,62.59,60.74$. DEPT-135 $\left(\mathrm{CDCl}_{3}, 75 \mathrm{MHz}\right): \delta(\mathrm{ppm})$ positive $128.56,128.50,128.33,128.28,128.06,127.89,127.78,86.14$, 81.47, 75.35, 63.11, 62.59; negative 73.41, 72.36, 72.29, 70.23, 60.74. FTICR-MS $m / z: 490.2230$ $[\mathrm{M}+\mathrm{H}]^{+}\left(\mathrm{C}_{29} \mathrm{H}_{32} \mathrm{NO}_{6}{ }^{+}\right.$requires 490.2224).

\section{Conclusions}

In summary, the access to both C-6 epimers of protected L-homoDMDP was achieved with high efficiency. The (6S)-epimer en-7 was prepared in 44\% overall yield from vinylpyrrolidine en-9 using the iodolactonization as a key step. The $(6 R)$-epimer en-8 was synthesized in 59\% overall yield from the known diol 13 through a 3-step-sequence-regioselective tritylation of diol 13, lactonization to give oxazolidinone and acidic hydrolysis of the trityl ether. The stereochemistry confirmation of L-homoDMDP was achieved through 2D-NMR and X-ray data based on the bicyclic oxazolidinone intermediate en-8. This work will lead to the collective synthesis of homoDMDP-related natural products and their analogues, and potentially to the unambigous disclosure of their stereochemistry.

\section{Supplementary Materials}

${ }^{1} \mathrm{H}$ and ${ }^{13} \mathrm{C}$-NMR spectra of compounds $e n-7$ and $e n-\boldsymbol{8}$ were available free of charge.

Supplementary materials can be accessed at: http:/www.mdpi.com/1420-3049/18/6/6723/s1.

\section{Acknowledgments}

This work is supported by The National Basic Research Program of China (No. 2012CB822101 and No. 2011CB808603), The National Natural Science Foundation of China (No. 21272240 and No. 21202008), The Chinese Academy of Sciences, and Excellent Young Scholars Research Fund of Beijing Institute of Technology.

\section{Conflict of Interest}

The authors declare no conflict of interest.

\section{References}

1. Welter, A.; Jadot, J.; Dardenne, G.; Marlier, M.; Casimir, J. 2,5-Dihydroxymethyl 3,4-dihydroxypyrrolidine dans les feuilles de Derris elliptica. Phytochemistry 1976, 15, 747-749.

2. Asano, N.; Nash, R.J.; Molyneux, R.J.; Fleet, G.W.J. Sugar-mimic glycosidase inhibitors: Natural occurrence, biological activity and prospects for therapeutic application. Tetrahedron Asymmetry 2000, 11, 1645-1680.

3. Watson, A.A.; Fleet, G.W. J.; Asano, N.; Molyneux, R.J.; Nash, R.J. Polyhydroxylated alkaloids-natural occurrence and therapeutic applications. Phytochemistry 2001, 56, 265-295.

4. Horne, G.; Wilson, F.X.; Tinsley, J.; Williams, D.H.; Storer, R. Iminosugars past, present and future: Medicines for tomorrow. Drug Discov. Today 2011, 16, 107-118. 
5. Asano, N.; Nishida, M.; Miyauchi, M.; Ikeda, K.; Yamamoto, M.; Kizu, H.; Kameda, Y.; Watson, A.A.; Nash, R.J.; Fleet, G.W.J. Polyhydroxylated pyrrolidine and piperidine alkaloids from Adenophora triphylla var. japonica (Campanulaceae). Phytochemistry 2000, 53, 379-382.

6. Shibano, M.; Nakamura, S.; Akazawa, N.; Kusano, G. Studies on the constituents of Broussonetia species. III. Two new pyrrolidine alkaloids, broussonetines $\mathrm{G}$ and $\mathrm{H}$, as inhibitors of glycosidase, from Broussonetia kazinoki SIEB. Chem. Pharm. Bull. 1998, 46, 1048-1050.

7. Trost, B.M.; Horne, D.B.; Woltering, M.J. Palladium-catalyzed DYKAT of vinyl epoxides: Enantioselective total synthesis and assignment of the configuration of (+)-broussonetine $\mathrm{G}$. Angew. Chem. Int. Ed. 2003, 42, 5987-5990.

8. Trost, B.M.; Horne, D.B.; Woltering, M.J. Palladium-catalyzed DYKAT of butadiene monoepoxide: Enantioselective total synthesis of (+)-DMDP, (-)-bulgecinine, and (+)-broussonetine G. Chem. Eur. J. 2006, 12, 6607-6620.

9. Hiranuma, S.; Shimizu, T.; Nakata, T.; Kajimoto, T.; Wong, C. Synthesis and inhibition analysis of five-membered homoazasugars from D-arabinofuranose via an SN2 reaction of the chloromethylsulfonate. Tetrahedron Lett. 1995, 36, 8247-8250.

10. Watson, A.A.; Nash, R.J.; Wormald, M.R.; Harvey, D.J.; Dealler, S.; Lees, E.; Asano, N.; Kizu, H.; Kato, A.; Griffiths, R.C.; et al. Glycosidase-inhibiting pyrrolidine alkaloids from Hyacinthoides non-scripta. Phytochemistry 1997, 46, 255-259.

11. Kato, A.; Adachi, I.; Miyauchi, M.; Ikeda, K.; Komae, T.; Kizu, H.; Kameda, Y.; Watson, A.A.; Nash, R.J.; Wormald, M.R.; et al. Polyhydroxylated pyrrolidine and pyrrolizidine alkaloids from Hyacinthoides non-scripta and Scilla campanulata. Carbohydr. Res. 1999, 316, 95-103.

12. Jones, S.B.; Simmons, B.; Mastracchio, A.; MacMillan, D.W.C. Collective synthesis of natural products by means of organocascade catalysis. Nature 2011, 475, 183-188.

13. Yu, C.; Asano, N.; Ikeda, K.; Wang, M.; Butters, T.D.; Wormald, M.R.; Dwek, R.A.; Winters, A.L.; Nash, R.J.; Fleet, G.W.J. Looking glass inhibitors: L-DMDP, a more potent and specific inhibitor of [small alpha]-glucosidases than the enantiomeric natural product DMDP. Chem. Commun. 2004, 1936-1937.

14. Hu, X.; Bartholomew, B.; Nash, R.J.; Wilson, F.X.; Fleet, G.W.J.; Nakagawa, S.; Kato, A.; Jia, Y.; Well, R.V.; Yu, C. Synthesis and glycosidase inhibition of the enantiomer of (-)-Steviamine, the first example of a new class of indolizidine alkaloid. Org. Lett. 2010, 12, 2562-2565.

15. Wang, W.; Huang, M.; Li, Y.; Rui, P.; Hu, X.; Zhang, W.; Su, J.; Zhang, Z.; Zhu, J.; Xu, W.; et al. A practical synthesis of sugar-derived cyclic nitrones: Powerful synthons for the synthesis of iminosugars. Synlett 2010, 488-492.

16. Yu, C.; Huang, M. Radicamines A and B: Synthesis and revision of the absolute configuration. Org. Lett. 2006, 8, 3021-3024.

17. Hu, X.; Jia, Y.; Xiang, J.; Yu, C. Exploratory studies en route to 5-alkyl-hyacinthacines: Synthesis of 5-epi-(-)-hyacinthacine A(3) and (-)-hyacinthacine A(3). Synlett 2010, 982-986.

18. Su, J.; Jia, Y.; He, R.; Rui, P.; Han, N.; He, X.; Xiang, J.; Chen, X.; Zhu, J.; Yu, C. A rapid synthesis of 2-aryl polyhydroxylated pyrrolidines. Synlett 2010, 1609-1616. 
19. Li, Y.; Huang, M.; Yamashita, Y.; Kato, A.; Jia, Y.; Wang, W.; Fleet, G.W. J.; Nash, R.J.; Yu, C. L-DMDP, L-homoDMDP and their C-3 fluorinated derivatives: Synthesis and glycosidase-inhibition. Org. Biomol. Chem. 2011, 9, 3405-3414.

20. Zhang, W.; Sato, K.; Kato, A.; Jia, Y.; Hu, X.; Wilson, F.X.; van Well, R.; Horne, G.; Fleet, G.W.J.; Nash, R.J.; et al. Synthesis of fully substituted polyhydroxylated pyrrolizidines via Cope-House cyclization. Org. Lett. 2011, 13, 4414-4417.

21. Zhang, Z.; Nakagawa, S.; Kato, A.; Jia, Y.; Hu, X.; Yu, C. A concise stereoselective synthesis of (-)-erycibelline. Org. Biomol. Chem. 2011, 9, 7713-7719.

22. Takebayashi, M.; Hiranuma, S.; Kanie, Y.; Kajimoto, T.; Kanie, O.; Wong, C. A versatile synthetic strategy for the preparation and discovery of new iminocyclitols as inhibitors of glycosidases. J. Org. Chem. 1999, 64, 5280-5291.

23. Bloch, R. Additions of organometallic reagents to $\mathrm{CN}$ bonds: Reactivity and selectivity. Chem. Rev. 1998, 98, 1407-1438.

24. Lombardo, M.; Fabbroni, S.; Trombini, C. Entropy-controlled selectivity in the vinylation of a cyclic chiral nitrone. An efficient route to enantiopure polyhydroxylated pyrrolidines. J. Org. Chem. 2001, 66, 1264-1268.

25. Delso, I.; Tejero, T.; Goti, A.; Merino, P. Synthesis of D-arabinose-derived polyhydroxylated pyrrolidine, indolizidine and pyrrolizidine alkaloids. Total synthesis of hyacinthacine $\mathrm{A}_{2}$. Tetrahedron 2010, 66, 1220-1227.

26. The crystal structure of $\mathbf{1 1}$ has been deposited at the Cambridge Crystallographic Data Center and allocated the deposition number: 928245.

27. Caderas, C.; Lett, R.; Overman, L.E.; Rabinowitz, M.H.; Robinson, L.A.; Sharp, M.J.; Zablocki, J. Total syntheses of allopumiliotoxins 267A, 323B' and 339A. Application of iodide-promoted iminium ion-alkyne cyclizations for forming allopumiliotoxin $\mathrm{A}$ alkaloids. J. Am. Chem. Soc. 1996, 118, 9073-9082.

Sample Availability: Not available.

(C) 2013 by the authors; licensee MDPI, Basel, Switzerland. This article is an open access article distributed under the terms and conditions of the Creative Commons Attribution license (http://creativecommons.org/licenses/by/3.0/). 